\title{
Financial Literacy of SME Managers' on Access to Finance and Performance: The Mediating Role of Financial Service Utilization
}

\author{
Juma Buhimila Mabula \\ Department of Business Administration \\ Harbin Institute of Technology \\ Harbin, China
}

\author{
Han Dong Ping \\ Department of Accounting \\ Harbin Institute of technology \\ Weihai, China
}

\begin{abstract}
Considering financial literacy as a central factor for consumer demand for financial services, we analyze its impact on access and actual use of financial services and its ultimate consequential reflections on SMEs performance in developing economies. By recognizing the important distinction between access and actual use of financial services this study uses the partial least square-structural equation modelling (PLSSEM) to estimate the conceptual model. The study reveal significant positive impact of financial literacy to financial access and performance of the firm. It was also discovered that there is significant positive direct impact of access to financial services into actual use of financial services and positive significant effect of the use of financial service on firm performance. The firm use of financial services has a significant mediating role on firm access to financial services-firm performance relationship. The implications of these findings offers foretastes on the need to deepen and widen the scope of SMEs managers' financial literacy for effective financial management and financial financing decisions. We argue distinct contributions of access and actual use of financial services construct on firm performance has to be given attention in attempt to avoid generalizing the phenomenon.
\end{abstract}

Keywords-Financial literacy; use of financial services; access to financial services; firm performance

\section{INTRODUCTION}

The significance of SMEs contribution to developed and developing economies is notably remarkable [1]-[4]. In developing economies having a small business has been a survival strategy for many individuals, due to thin base and inadequate public and private formal employment [5]. The development of SMEs is hampered by number of factors which may include access to finance, lack of managerial skills, poor equipment and technology, regulation system and absence of access to international markets [6]. The lack of managerial know how places a significant threat to SMEs development [7]. Despite the numerous initiatives to provides training to SMEs owners/managers' the skill gap is still large, this is because most of SMEs cannot afford the cost of deliberate skills upgrade through training and advisory services [8]. Moreover SMEs are considered to be informationally impervious due to their less external monitoring and thin reporting requirements as it can be distinguished from large firms [9].

Becoming an entrepreneurial manager of a venture can be exceedingly risky if there is little or no confidence in financial management [10]. The cost of information and the probability that people utilize a financial resource once they are aware of it depends on the incentives attached to it [11]. The emerging trends posit the low level of consumption of formal financial services and low level of participation into financial markets in developing economies as a function of financial literacy [12]. The firm's use of financial products may not just be an indicator for having access to such products but also having skills and knowledge of managing such products.

Situating access to financial services in developing economies, the global statistics for financial inclusion for 2014 data from Global Findex database stress that $62 \%$ of the adult own an account at a formal financial institution, this includes banks and mobile money services. With the innovation of the mobile banks the account ownership has substantially increased in developing economies reaching to $54 \%$ of the population in 2014 [13]. Beside the increase the share of excluded individual is still high in developing economies as compared to high income countries. Also [14] claim that despite the efforts that has been under move by the developed economies to enhance the provision of quality and sustainable formal financial services like credit, savings, payment systems, insurance and pensions to mention a few, most of the developing economies still have a large number of population who lack access to basic financial services.

While the problem of SMEs access to finance has been overly studied and many studies has embarked on analyzing it by employing constructs on the supply side like number of accounts providers has, and number of ATM present in the area [15]. Such approach has a detriment of not harnessing the actual facts from individual/firms consumption or nonconsumption of such services. The approach by surveying the demand side, where by consumers offers their ground views all else unchanged seems to be compelling. A plausible functioning financial market not only need good infrastructure but also informed consumers [16]. Few studies in developing economies has attempted to analyze the access to financial services based on consumers' financial literacy. [17] Analyzed the impact of individual financial literacy on access to financial services in Kenya using national financial access data. [18] Approached their cross countries analysis on the role of financial literacy education on financial inclusion. Even then these studies had has little to do with the distinction of access 
and actual use of financial service, though connected these constructs would have different inferences.

Could the low level of participation in the formal financial market in developing economies be attributed to lack of financial literacy by SMEs? Do firm managers' utilizes their financial literacy to take advantage of available financial products? In the presence of actual use of financial products how does financial literacy and access to financial services impact firm performance? If the financial services available would financial literacy explain the use or the non-use of such services by consumers? What are the mediation roles of financial utilization on financial literacy and or access to financial services-firm performance relationship?

Therefore this study focuses on answering these questions, realizing the dearth of rigorous studies on the concept financial literacy, use and access to finance in developing economies, this scrutiny therefore analyze the impact of financial literacy on SMEs financial access and performance in developing economies. Further we attempt to analyze the mediation role of financial utilization on financial literacy-firm performance and financial access-firm performance relationship. Moreover this study contribute by examining access and use of financial services determinants separately contrary to most studies which studied financial access determinant and employ the use of as a proxy.

\section{CONCEPTUAL FRAMEWORK AND HYPOTHESIS DEVELOPMENT}

This study is motivated by theory of bounded rationality which stress that individuals make decisions, whereby their rationality is limited by their ability to manage the decision problem, intellectual limitations and time available. Consumers in this view act as if seeking for satisfaction rather than focusing on an optimal solution. Bounded rationality impose the idea that individuals take shortcuts that may lead to suboptimal decision-making [19]. This study conceptually analyze the artifactual decisions taken by SME managers at firm level, based on their level of financial literacy which entails financial knowledge, attitudes and behavior will be a base for the decision to use or not to use a certain financial product/service even though is available. This phenomenon implicate supplier of financial services to not only invest of their services making accessible but also strategizing on initiatives that will inspire responsible consumers.

Financially literate consumer is able to identify financial products or services that meet his/her needs, can independently obtain and assess any financial advice and be more likely curb the impact of abusive exploitative practices and scams [20]. Financial literacy enhance consumer effective participation in financial market [21].

The general conceptual framework for this study is depicted in fig. 1

Where by FL=Financial Literacy, UFS= Use of Financial Services, $\mathrm{AC}=$ Access to finance, $\mathrm{PF}=$ Firm performance, UFS'=Mediating variables on AW-FP relationship, UFS' '=Mediating variable on AC-FP Relationship

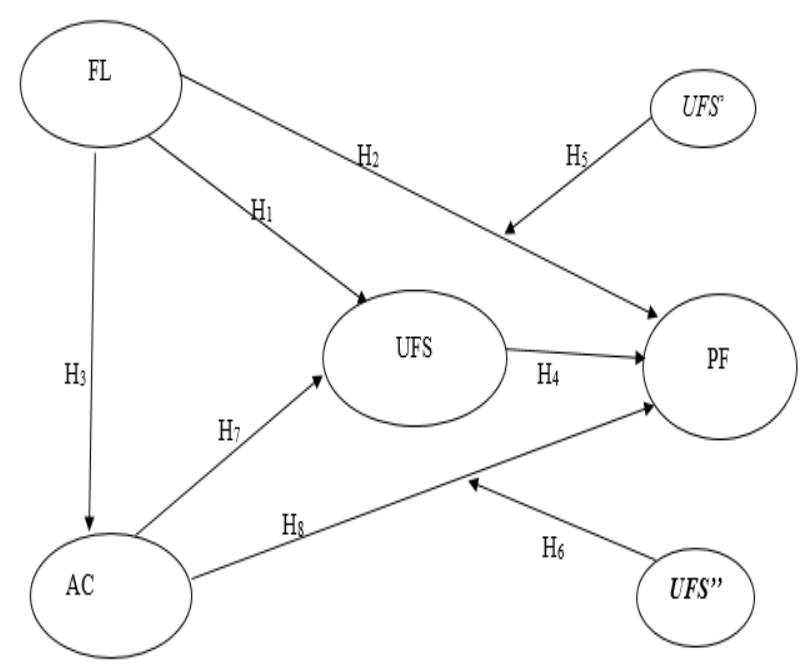

Fig. 1. The General study Model

Financial literacy has been theorized to promote active participation of individual and firms in the formal financial markets [11], [21]. Managers in firms with considerable financial literacy will be more active in making optimal choice of the funding sources by analyzing cost, benefits and risk associated with the potential funds. The British Business Bank (BBB) reveal that the firms' awareness to alternative funding sources is positively related to the participation of firms in the finance market [22]. Also literature evidence that there is a positive correlation between financial literacy to firm performance. [23] Stated that a major hindrance to performance growth of sustainable small and SMEs managers' across developing world is the lack of knowledge, skills, attitude and awareness to cope and manage finances. The dearth of business information and the incompetence of the SMEs management is singled out as the as one of the reason for firm not to access available finances from commercial banks [24]. Therefore we argued that:

Hypothesis $\mathrm{H}_{1}$ Financial literacy has a positive impact on SMEs use of financial products in developing economies

Hypothesis $\mathrm{H}_{2}$ Financial literacy has a positive impact on SMEs performance in developing economies

Hypothesis $\mathrm{H}_{3}$ Financial literacy has a positive impact on firm financial access in developing economies

As it has been exemplified access to financial services doesn't necessarily amount to using it. Availability is inevitable but not a sufficient premise for use [25]. There is a clear difference between a mere access to and actual use of financial services [26]. Access to financial services is not to be equaled to the actual use of financial services. Individuals and firm might have access to financial services due to social or economic reasons decide not to use them. The outreach indicators employed to determine the actual uses of financial services and all these indicators showed a positive correlation on the firm performance indicators. Firms has claimed their non-use of certain financial services is due to cost and affordability. The high minimum deposits, high administrative fees, high fixed cost for loan application and high rejection rate 
all these contribute problem. Financial institutions collateral demand to the poor borrowers and lack of financial literacy adds to the challenge. Therefore it is hypothesized that:

Hypothesis $\mathrm{H}_{4}$ : The use of financial services has positive impact on firm performance in developing economies.

The availability of financial services is compulsory condition for access from supply side and in addition to this convenience imply efficient access and use of such a service [27]. Use of finance refers to the actual consumption of the financial service. The usage can be referred at the point of intersection of the supply and demand curve of the financial services [25]. The use of financial services entails quality, regularity and the use duration which is subject to voluntary and involuntary exclusion probably more influenced by factors from the supply side connected to information asymmetry [28]. The mediating role of actual use financial services emanate from the fact that, the use of services is an action which is preceded by knowledge of such services and access to it. Without consumption of a particular financial services having knowledge and access to it won't make a resultant impact on SME. Therefore theoretically the use of financial services is supposedly to mediate the relationship of financial literacy/ access to financial services and firm performance. We therefore propose that:

Hypothesis $\mathrm{H}_{5}$ Use of financial services mediate the financial literacy-firm performance relationship in developing economies

Hypothesis $\mathrm{H}_{6}$ Use of financial services mediate the access to finance-firm performance relationship in developing economies

Access to financial services hypothetically has a positive correlation is into the actual use of such services. The more the financial products available at low cost the more the supposedly use by the economic agents. A consented theory propose that a deeper and wider financial sector can contribute to enhanced performance of SMEs. Firms which have access to finance has an opportunity to manage their risks, widen the menu of choices and the consumption patterns. For instance credit as an important instrument deemed to improve performance of firms by enhancing the productive capacity derived from the investment financed [29].

Hypothesis $\mathrm{H}_{7}$ Access to finance has a positive impact on utilization of financial services in developing economies

Hypothesis $\mathrm{H}_{8}$ Access to finance has a positive impact on firm performance in developing economies

\section{LITERATURE}

First of all it is important to grasp the meaning of the key terms and their essence niceties in the context of this study.

Financial literacy refers to the possession of the right financial knowledge, skills, attitudes and behavior [30]. At OECD/INFE defines financial literacy as a combination of awareness, knowledge, skill, attitude and behavior necessary to make sound financial decisions and ultimately able to achieve financial wellbeing [30]. At another level financial literacy has been synonymously considered to be the same as financial literacy [31], [32].

Financial access to financial services refers to the availability of the supply of reasonable quality financial services. [33] Extend the definition of access to finance to mean the ability of individuals or enterprises to attain financial services, which may include credit, deposit, payments, insurance, and other risk management services. Financial utilizations means the actual use/consumption of financial services [12].

The terms utilization and access to financial services has been used conjointly and interchangeably by many studies even though they overlap they distinctly mean different things. To understand well the conceptualization of the differences between use and access to financial services [34] gives an illustration of worthy individuals in advanced financial markets, still they might not use some of the financial services even though they are readily available and they can afford to pay. Nevertheless every individual and firms at some points in time need a certain kind of financial product. The difference between access and actual utilization of financial services could be analyzed by a demand-supply structure. As access refers to supply while the use refers to the intersection between the supply and demand schedules [25]. Voluntary exclusion doesn't necessarily mean the service is not available or is rationed, the decision consumers' to utilize financial services is based on their financial attitude and behavior.

Financial inclusion is the term that exclusively embrace financial access and use together. [35] Define financial inclusion as "the process of insuring access to appropriate financial products and services needed by all sections of society including vulnerable groups such as weaker sections and low income groups at an affordable cost in a fair and transparent manner by main stream institutional players" .Financial inclusion focuses on making easy access to financial services to large disadvantaged people. The lack of financial access limit the array of services and credits to individual, household and enterprises. [36] Mention of factors that are limiting access to finance to include place of living, absence of legal identity and gender biasness, limited knowledge of financial services, level income and bank charges, rigid terms and conditions and the type of business. [37] Offers glimpses of the principle of how to measure countries progress towards enabling access to and driving usage of the different financial products. in attempt to define access and usage in accurate and comprehensive way, they identified levels of availability of financial product, actual ownership of the product, the use of the product over a specified time and how much the product is used to address the consumer's needs.

\section{A. Financial Literacy and Financial Inclusion}

Financial literacy stem as an important constituent of consumer effective participation in the formal financial market. The benefits derived from enhancing it has dual benefit to consumers and suppliers of financial services [17]. While financial literacy provides the apt information for the consumer in the financial market. Provided need and access to certain financial product, the attitude and behavior will enable the consumer to be active partaker of the financial product. [16] 
Argues that access to financial services and particularly having a bank account, the marginal benefits of financial literacy decreases with higher financial depth, indicating that financial access and financial literacy are supposedly substitutes. However if inclusion is all about access and use of financial services, financial literacy has a complementary effect on financial depth at higher level of comprehension and therefore they reinforce each other.

\section{B. Role of Financial Institutions on Financial Literacy and Financial Access}

Banks has played a big role in providing awareness and appropriate use of financial services they offer to their clients. The role of banks in provision of financial education shore up their unique position in the financial system, as they act as a bridge in theoretical economic concepts such as scarcity and opportunity costs, with real money in the pocket services and supplement them with the necessary financial products. The access to low cost financial products is mainly valuable for unbanked and under-banked clients. Therefore connecting financial education and financial products allows all individuals to become full incorporated in the traditional financial system [38].

[14] Examined the impact of presence of mobile financial services in Sub Saharan Africa and found that the presence of mobile banking has positively enhanced the saving behavior, and it stands as an avenue for promoting financial inclusion especially to the poor and low income groups constrained to financial access. By reforming the banking sector and strengthening the financial sector legal and regulatory framework and modernizing the financial sector infrastructure and extending the range of basic financial products and services to underserved zones access to finance for households and firms will be enhanced.

\section{Financial Literacy for SMEs}

The Bank Association of South Africa as cited by [39] defines financial literacy for SMEs as one which has the following qualities: first has an adequate level of personal entrepreneurial competencies, personal finance skills, and business management skills; has an appropriate level of understanding of functional financial management systems. Second, has appropriate level of understanding of SME lifecycle funding and other financial service requirements. third, understands legal, regulatory and tax issues as they relate to financial matters and lastly understands the range of legal recourses it can resort to when necessary, and namely, in case of bankruptcy or other situations of financial distress [40].

A financially literate SME owner/manager is considered to know the most suitable financing and financial management options for his/her business at various growth stages, knows where to attain the most appropriate financial products and services; and interacts confidently with the suppliers of these products and services. Is familiar with the legal and regulatory framework and his/her rights and recourses [41].

The ability of a small business owner/managers to gather information from financial statement has a big role to play in business success, because it supports them to detect signs of failure, and overall health status of the venture [42]. The general stance of firm financial literacy stems on manager's ability to translate their personal finance into a business venture context. Financial literacy in the new business reality is defined as the competence to adequately manage financial resources over the lifecycle and effectively link with financial products and services [43].

\section{Access to Finance and Firm Performance}

[44] Using data from enterprise survey examined access to finance and performance of the firm in African context. Using the subjective measure they found that lack of access to finance exert a significant negative effect on firm growth. And the objective measures proved that firms that are not financially constrained has high rate of growth than the credit constrained ones. Also [45] similarly studying the impact of financial inclusion and bank concentration on firm performance, they found that the financial inclusion on distribution of financial service across firm has a positive impact onto firm growth.

\section{E. SME Definition in the Context}

Since there is no universally accepted SME definition, the nomenclature in this study context is used to mean Micro, Small and Medium enterprises. It is sometimes referred to as micro, small and medium enterprises (MSMEs). The definition is derived from Tanzania mainland where the survey was relevantly conducted. The SMEs cover economic activities mainly manufacturing, mining, commerce and services. The commonly used benchmarks are total number of employees, total investment and sales turnover. In this standpoint, micro enterprises are those engaging up to 4 people, in most cases family members or employing capital amounting up to Tanzania Shilings (Tshs.) 5.0 million. The majority of microenterprises fall under the informal sector. Small enterprises are mostly formalized undertakings engaging between 5 and 49 employees or with capital investment from Tshs 5million to Tshs. 200million. Medium enterprises employ between 50 and 99 people or use capital investment from Tshs. 200 million to Tshs. 800 million [46].

\section{METHODOLOGY}

The sample for our study was composed of SMEs managers from region of Morogoro and Dar es Salaam from Tanzania. From previous research firm managers form an interesting group to analyze the level of financial literacy and its consequences to their firm operations in developing economies, considering the fact that they are involved in their daily financial management of the firm [12], [48].

We used a convenient sampling because of the locational and financial limitations. We used a self-administered questionnaire of which we had to physically distribute it to the premise of the firm and collet it thereon. The questionnaire comprehensively was designed to capture the SMEs managers' financial literacy at personal and firm level. And this study is part of such a comprehensive questionnaire. All questions used in this study has was 5 point likert scale questions. To encourage participation and minimize non responses the questionnaire was preceded by the introduction letter and personal expression for respondents to know that the study was solely academic based. The survey was piloted in the field and there after the instruments was refined by experts from the 
field. The questionnaire completely filled was 311 even though we managed to reach 520 firms, a response rate of about $60 \%$. Cronbach's alpha test was used to verify the quality and consistency of our instrument.

\section{A. Variable Definition and Sources}

Table I presents definitions of the variables indicators and their respective sources.

TABLE I. VARIABLE DEFINITION AND SOURCES

\begin{tabular}{|l|l|l|}
\hline Variables & Indicators & Source \\
\hline FL & $\begin{array}{l}\text { General financial literacy (GFL), } \\
\text { Financial knowledge (FK), Financial } \\
\text { attitude (FA), and Financial Behavior } \\
\text { (FB) }\end{array}$ & $\begin{array}{l}\text { Atkinson, Adele } \\
\text { Messy, Flore- } \\
\text { Anne 2013 }\end{array}$ \\
\hline UFS & $\begin{array}{l}\text { Easiness of having personal bank account } \\
\text { (UFSi), using the firm bank account, } \\
\text { banking of daily undertakings (UFSii), } \\
\text { Reinvesting the cash balances (UFSiii), } \\
\text { having credit from financial institution } \\
\text { (UFSiv). }\end{array}$ & $\begin{array}{l}\text { Olawale Fatoki, } \\
\text { AC }\end{array}$ \\
\hline $\begin{array}{l}\text { Easiness of getting funds from financial } \\
\text { institutions (ACi), limited availability of } \\
\text { funds for firm (ACii), and the cost of } \\
\text { acquiring funds is too high (ACiii). }\end{array}$ & $\begin{array}{l}\text { World Bank's } \\
\text { enterprise survey }\end{array}$ \\
\hline PF & $\begin{array}{l}\text { Steady firm growth (PFi), steady increase } \\
\text { number of employees (PFii), increase in } \\
\text { productivity (PFiii) and ability to buy } \\
\text { fixed assets (PFiv) }\end{array}$ & $\begin{array}{l}\text { World Bank's } \\
\text { Enterprise survey }\end{array}$ \\
\hline
\end{tabular}

\section{B. Measurement of Variables}

The constructs in this study were measured using a multiitem scale, all measures were adapted from the previous studies. Each measure was anchored on five-point scale. The survey instruments form the measures was pre-examined by three different business academics to make solid wording and clarity of the questions. To establish the consistent with the spirit of the original instrument we performed instrument factor analysis before including them in the PLS model.

\section{1) Financial Literacy}

Financial literacy was adopted from [18] study, where by there is a question on self-rating financial literacy, financial knowledge, financial attitude and financial behavior. Then we adopted the questions and stylized them into a 5-point likert scale except for financial knowledge. Financial knowledge construct has a multiple choice questions to test the apt knowledge of consumers of financial literacy, correct answer and categorized them into low, medium and high scores.

\section{2) Use of Financial Services}

We also adapted part of [47] questions on understanding financing sources because they were fit into the use of financial services. From thence we made a five point likert scale to actually draw a behavioral conclusions from the managers. The principal factor analysis yielded a single factor solution with eigenvalues exceeding 1 and factor loading ranging from 0.874 to 0.964 . This factor explained $69.66 \%$ of the total variance.

\section{3) Access to Finance}

Coupled with the details from the World Bank enterprise survey, we created questions for access to finance. We created five-point scale subjective measures on easy access, availability and cost of funds to the firm. The principal factor analysis results were single factor solution factor loading ranging from 0.962 to 0.989 . This factor explained $34.954 \%$ of the total variance.

\section{4) Firm Performance}

We adapt construct from the Word Bank enterprise survey for performance of the firm. Then we created a five point likert scale measures to capture our respondents responses on the firm performance. The construct focused on sales growth, number of employees' growth, productivity and ability to purchase fixed assets. After performing the principal factor analysis our results gave a single factor solution, factor loading ranging from 0.698 to 0.826 . The factor explained 53.139 of the total variance.

\section{Descriptive Statistics and Control Variables}

We also collected information about the individual and firm industry for our respondents to add to the foundational constructs of our study interest. These variables were included in our statistical model to partial out their effects on our dependent variables. Table II shows demographic information at personal level includes gender and level of education. The reminder of the variables are at firm level with includes type of business, business location, age, and number of employees. None of our control variables were significantly related to our dependent variables.

TABLE II. SUMMARY OF RESPONDENTS’ DEMOGRAPHIC CATEGORIES

\begin{tabular}{|c|c|c|c|}
\hline & & Number & Percentage \\
\hline \multirow{2}{*}{ Gender } & Male & 164 & $52.9 \%$ \\
\hline & Female & 146 & $47.1 \%$ \\
\hline \multirow{4}{*}{ Education Level } & Primary & 11 & $3.5 \%$ \\
\hline & Secondary & 87 & $28.1 \%$ \\
\hline & College & 134 & $43.2 \%$ \\
\hline & University & 78 & $25.2 \%$ \\
\hline \multirow{6}{*}{ Business type } & Wholesale and Retail & 101 & $32.2 \%$ \\
\hline & Agricultural & 56 & $18 \%$ \\
\hline & Construction & 31 & $10.0 \%$ \\
\hline & $\begin{array}{l}\text { Food and } \\
\text { Accommodation }\end{array}$ & 31 & $10.0 \%$ \\
\hline & Manufacturing & 30 & $9.7 \%$ \\
\hline & Others & 61 & $19.1 \%$ \\
\hline \multirow{2}{*}{ Location } & Rural & 127 & $41 \%$ \\
\hline & Urban & 183 & $59 \%$ \\
\hline \multirow{4}{*}{ Firm Age } & Below 1 Year & 39 & $12.6 \%$ \\
\hline & 1-5 Years & 132 & $42.6 \%$ \\
\hline & 6-10 Years & 100 & $32.3 \%$ \\
\hline & More than 10 Years & 39 & $12.6 \%$ \\
\hline \multirow{3}{*}{$\begin{array}{l}\text { Number of } \\
\text { employees }\end{array}$} & 1-5 Micro & 144 & 46.5 \\
\hline & 6-49 Small & 147 & 47.4 \\
\hline & 50-99 Medium & 19 & 6.1 \\
\hline
\end{tabular}

\section{Results}

We use SPSS version 23 to obtain the descriptive statistics and then SmartPLS for estimation of Partial Least SquareStructural Equation Modelling (PLS-SEM).We use PLS-SEM approach because of its exceptional ability and fewer 
assumption than covariance-based structural modelling [49]. PLS recognized to be a component based approach that attempt to maximize variance explained and minimize error. With PLS we are able to examine theory and measures simultaneously. PLS-SEM has an advantage of handling small sample sizes and no assumptions for particular scale and normality of the data distribution [50]. [51]. Basing on the rule of sampling that the minimum sample size for PLS modeling have to be ten times of the portion of the model that require multiple regression. In our model we had 3 independent variables, allowing us to use a sample of size of 30 . Therefore our sample of 310 respondents was more than adequate for PLS modelling.

\section{E. The Measurement Model}

The model estimate the relationships between manifest variables and latent variables hence we have the inner and outer model. In the model we estimate and evaluate the reliability and validity of the model. Table III the indicator's reliability, the composite reliability, convergent validity, and the descriptive statistics of our study model. For internal consistency of our model. [52] Suggests using factor loading instead of Cronbach alpha. the factor loading of 0.7 is always preferred but 0.4 or higher loading is acceptable for exploratory research [53], [54] in our model the minimum factor loading is 0.438 and the maximum is 0.911 all being in the acceptable range. Complementing with the factor loading our result shows that all factor were loaded significantly at $p<0.001$ and $p<0.05$ one-tailed significant levels. With these results we confirm that all our constructs has satisfactory reliability.

\section{1) Model Internal Consistency}

The model internal consistency or reliability is calculated by the formula in equation 1 .

$$
\left(\sum \lambda_{i}\right)^{2} /\left[\left(\sum \lambda_{i}\right)^{2}+\sum\left(1-\lambda_{i}{ }^{2}\right)\right]
$$

Whereby: $\lambda_{i}$ represent the ith component loading and $1-\lambda_{i} 2$ refer to the ith error variance. In this stance composite reliability measure is used as an alternative to Cronbach's alpha. This is undertaken on the basis that composite reliability weighs each factor loading. The threshold of $\geq 0.7$ composite reliability is regarded to be suitable [55]. In this study model result shown in table III provides all composite reliability to be above 0.7 confirming that the model possesses enough internal consistency.

\section{2) Convergent and Discriminant Validity}

To assess the convergent and discriminant validity we consider the Average Variance Extracted (AVE) calculated for each component. The AVE measures the degree to which scale items for each items are correlated. 0.5 or above AVE is considered to be adequate [54], [56].

AVE can be calculated by the equation 2 :

$$
\left(\sum \lambda_{i}\right)^{2} /\left[\sum \lambda_{i}^{2}+\sum\left(1-\lambda_{i}^{2}\right)\right]
$$

Whereby: $\lambda_{i}$ represent the ith component loading and $1-\lambda_{i} 2$ refer to the ith error variance

In our model the minimum AVE is 0.503 and the maximum AVE is 0.603 as reported in table III. Therefore our results demonstrates adequate convergent validity.

\begin{tabular}{|c|c|c|c|c|}
\hline $\begin{array}{l}\text { Latent } \\
\text { Variable }\end{array}$ & Mean & SD & Loading & t-statistics \\
\hline \multicolumn{5}{|c|}{ Financial Literacy (composite reliability $=0.726 ; A V E=0.503$ ) } \\
\hline GFL & 0.417 & 0.154 & 0.438 & $2.845^{* *}$ \\
\hline FK & 0.593 & 0.140 & 0.607 & $4.341 * * *$ \\
\hline FA & 0.718 & 0.099 & 0.731 & $7.409 * * *$ \\
\hline FB & 0.716 & 0.100 & 0.730 & $7.267 * * *$ \\
\hline \multicolumn{5}{|c|}{ Use of financial services (composite reliability $=0.773 ; A V E=0.511$ ) } \\
\hline UFSi & 0.853 & 0.137 & 0.885 & $6.449 * * *$ \\
\hline UFSii & 0.702 & 0.169 & 0.720 & $4.297 * * *$ \\
\hline UFSiii & 0.513 & 0.194 & 0.551 & $2.845^{* *}$ \\
\hline UFSiv & 0.496 & 0.180 & 0.530 & $2.947 * *$ \\
\hline \multicolumn{5}{|c|}{ Access to financial services (composite reliability $=0.761 ; A V E=0.522)$} \\
\hline $\mathrm{ACi}$ & 0.718 & 0.174 & 0.753 & $4.318 * * *$ \\
\hline ACii & 0.808 & 0.148 & 0.838 & $5.650 * * *$ \\
\hline ACiii & 0.544 & 0.176 & 0.544 & $3.091 * * *$ \\
\hline \multicolumn{5}{|c|}{ Firm performance $($ composite reliability $=0.818 ; A V E=0.605)$} \\
\hline $\mathrm{PFi}$ & 0.762 & 0.098 & 0.769 & $6.732 * * *$ \\
\hline PFii & 0.901 & 0.038 & 0.911 & $15.423 * * *$ \\
\hline PFiii & 0.609 & 0.136 & 0.628 & $6.449 * * *$ \\
\hline
\end{tabular}

TABLE III. RELIABILITY AND CONVERGENT VALIDITY (AVE)

The discriminant validity was examined by comparing the square roots of the AVEs of the constructs with the correlation coefficient between the constructs [55]. The result of discriminant validity is shown in table IV where by the correlation coefficients are in off-diagonal, and the square root of the AVEs are shown on diagonal. Our model indicated that there is adequate discriminant validity due to the fact that all the square root of the AVEs are greater than the correlation coefficients.

TABLE IV. DISCRIMINANT VALIDITY AND HETERO MONOTRAIT RATIO (HTMT) IN PARENTHESIS

\begin{tabular}{|l|l|l|l|l|}
\hline & AC & FL & PF & UFS \\
\hline AC & 0.686 & & & \\
\hline FL & $0.085(0.722)$ & 0.638 & & \\
\hline PF & $-0.283(0.353)$ & $-0.295(0.572)$ & 0.778 & \\
\hline UFS & $-0.334(0.562)$ & $-0.294(0.370)$ & $0.229(0.438)$ & 0.686 \\
\hline
\end{tabular}

Diagonal item are square root of $A V E$, and non-diagonal elements are the correlation of the elements

The other approach to confirm the model discriminant validity is to examine the cross loading. In principle indicators are supposed to load well on their target factors and the cross loading not supposed to be significant. The heuristic limit loading for cross loading should be $\leq 0.3$ [57]. From table V note that all cross loading are $\leq 0.3$, further endorsing that our model has discriminant validity. 
TABLE V. VARIANCE INFLATION FACTOR (VIF) AND CROSS LOADING

\begin{tabular}{|l|l|l|l|l|l|}
\hline & VIF & AC & FL & PF & UFS \\
\hline ACi & 2.208 & 0.753 & -0.234 & 0.154 & -0.145 \\
\hline ACii & 2.217 & 0.838 & 0.288 & 0.179 & -0.207 \\
\hline ACii & 1.011 & 0.544 & -0.303 & 0.145 & -0.302 \\
\hline FA & 1.690 & -0.168 & 0.731 & -0.239 & 0.047 \\
\hline FB & 1.624 & -0.305 & 0.730 & -0.273 & 0.047 \\
\hline FK & 1.022 & -0.302 & 0.607 & -0.223 & 0.200 \\
\hline GFL & 1.089 & -0.154 & 0.438 & -0.144 & 0.127 \\
\hline PFi & 1.533 & 0.185 & -0.273 & 0.769 & -0.272 \\
\hline PFii & 2.533 & 0.246 & -0.324 & 0.911 & -0.231 \\
\hline PFiii & 1.478 & 0.062 & -0.224 & 0.628 & -0.140 \\
\hline UFSi & 2.801 & -0.259 & 0.184 & -0.196 & 0.885 \\
\hline UFSii & 2.134 & -0.264 & 0.102 & -0.161 & 0.720 \\
\hline UFSiii & 2.420 & -0.123 & 0.142 & -0.214 & 0.551 \\
\hline UFSiv & 1.082 & -0.201 & 0.052 & -0.209 & 0.530 \\
\hline
\end{tabular}

\section{3) Common Method Bias}

Because of the self-reported data there is a possibility of existence of common method bias. The common method bias can be caused by a number of factors which may include consistency and social interest [58]. In attempt to find out whether our data was affected by common method bias, we use the approach by [59]. In this procedure we included in the PLS model a common method factor where by this common factor indicators included all principal constructs' indicators and then we calculated the variance 's indicators essentially exemplified by the principal construct and by the method. Our results as shown in table VI. The average variance of the indicators is 0.523 , whereas the average method variance is 0.240 , from this we obtain the ratio of principal constructs variance to method variance to be about 2.2:1. Our result also shows that all the factor loadings for the method variances are not significant. Given the higher variance of the substantive indicators and the insignificant results on the method variance, then we determine that the common method bias is unlikely to be a serious concern for our study.

Also the common method bias problem was assessed by the adopting the approach used by [60]. The practice is to assess the Variance Inflation Factor (VIF) if they are $\leq 3.3$ for the model which has passed convergent and discriminant validity evaluation. The VIF shown in table $\mathrm{V}$ presents all results to be less than 3.3, further confirming that our scrutiny was not affected by common method bias.

TABLE VI. COMMON Method Bias ANALysis

\begin{tabular}{|c|c|c|c|c|c|}
\hline \multirow[b]{2}{*}{ Construct } & \multirow[b]{2}{*}{ Indicator } & \multicolumn{2}{|c|}{$\begin{array}{l}\text { Substantive } \\
\text { Factor Loading }\end{array}$} & \multicolumn{2}{|c|}{$\begin{array}{l}\text { Method Factor } \\
\text { Loading }\end{array}$} \\
\hline & & $(R 1)$ & $R 1^{2}$ & $(\mathrm{R} 2)$ & $R 2^{2}$ \\
\hline \multirow{4}{*}{ Financial Literacy } & GFL & $0.757 * * *$ & 0.573 & 0.492 & 0.242 \\
\hline & FK & $0.617 * *$ & 0.381 & 0.509 & 0.259 \\
\hline & FA & $0.767 * * *$ & 0.588 & 0.443 & 0.196 \\
\hline & FB & & & & \\
\hline \multirow{4}{*}{$\begin{array}{l}\text { Use of financial } \\
\text { services }\end{array}$} & UFSi & $0.907 * *$ & 0.823 & 0.560 & 0.314 \\
\hline & UFSii & $0.705 * *$ & 0.497 & 0.451 & 0.203 \\
\hline & UFSiii & $0.591^{* *}$ & 0.241 & 0.386 & 0.149 \\
\hline & UFSiv & $0.477 * *$ & 0.228 & 0.318 & 0.101 \\
\hline \multirow{3}{*}{ Access to finance } & $\mathrm{ACi}$ & $0.828 * *$ & 0.686 & -0.498 & 0.248 \\
\hline & ACii & $0.880^{* * * *}$ & 0.774 & -0.602 & 0.362 \\
\hline & ACiii & 0.429 & 0.184 & 0.403 & 0.162 \\
\hline \multirow{3}{*}{ Firm Performance } & PFi & $0.919 * * *$ & 0.845 & -0.547 & 0.299 \\
\hline & PFii & $0.729 * * *$ & 0.531 & -0.401 & 0.161 \\
\hline & PFiii & $0.667 * * *$ & 0.445 & -0.650 & 0.423 \\
\hline \multicolumn{2}{|l|}{ Average } & 0.713 & 0.523 & 0.067 & 0.240 \\
\hline
\end{tabular}

\section{RESUlTS AND DiscUSSION}

After verification of the model measurement and confirming no worry of the common method biases we carry on examining the structural model. Table VII and fig. 2 provides us with the detailed results of the PLS analysis. Sheet A shows the direct relationship and sheet B shows an indirect relationship.

TABLE VII. PATH CoEfFicient AND T-STATistics Results

\begin{tabular}{|l|l|l|l|l|}
\hline & Sample & Mean & Standard Deviation & T Statistics \\
\hline AC->PF & 0.017 & 0.013 & 0.122 & 0.135 \\
\hline AC->UFS & 0.298 & 0.314 & 0.052 & $2.184^{*}$ \\
\hline FL->AC & 0.448 & 0.467 & 0.075 & $5.996^{* * *}$ \\
\hline FL->PF & 0.309 & 0.317 & 0.108 & $2.855^{* *}$ \\
\hline FL->UFS & 0.044 & 0.051 & 0.136 & 0.326 \\
\hline UFS->PF & 0.223 & 0.243 & 0.097 & $2.038^{*}$ \\
\hline
\end{tabular}

$\mathrm{H}_{1}$ predicted a positive relationship between SMEs managers' financial literacy and use of financial products in developing economies. The PLS structural path on this shows insignificant results. This explains that financially literate doesn't necessarily mean using them effectively. Other factors like the access to such funding sources might explain the relationship between financial literacy and the use of financial services by SMEs managers in developing economies.

$\mathrm{H}_{2}$ predicted the positive association between SMEs managers' financial literacy and firm performance in developing economies. The structural model shows a significant result at $(\mathrm{p}<0.01)$ in the hypothesized direction. The results suggest that the SMEs managers' financial literacy is such an important driver for the firm performance. Therefore $\mathrm{H}_{2}$ is supported by our model.

$\mathrm{H}_{3}$ Also predicted that SMEs managers' financial literacy has a positive impact on firm financial access in developing. The results from the structural PLS model shows a significant results at $(\mathrm{p}<0.01)$ in the hypothesized direction. Implying that the more the SMEs managers in developing economies be financially literate the more enhancement of access to finance by the firm. Therefore $\mathrm{H}_{3}$ is supported by our model. The significant results in this hypotheses might explain the reasons for insignificant results in $\mathrm{H}_{1}$.

In $\mathrm{H}_{4}$ we hypothesized that there is a positive relationships between the use of financial services and the firm performance in developing economies. In this we have a significant result also at $(\mathrm{p}<0.05)$ from the model. This shows that as firms in developing economies use more of formal financial services there will also be improvement in the firm performance. Therefore $\mathrm{H}_{4}$ is also supported by our model.

$\mathrm{H}_{7}$ projected that there is a positive relationship between firm accesses to finance and the utilization of the financial services. The results of our PLS structural model provide that there is significant result at $(\mathrm{p}<0.01)$ in the predicted direction. Confirming our prediction that as more access to finance firms 
has in developing economies they are likely to use more financial services. Hence $\mathrm{H}_{7}$ is supported in our model.

$\mathrm{H}_{8}$ Also predicted appositive association of access to financial services on the performance of the firm. Our PLS structural model shows insignificant results. Therefore $\mathrm{H} 8$ is not supported by our model. This results may explain that there might be indirect relationship between access to finance and performance of the firm. We therefore take care of the case by analyzing the mediation role of use of financial services to access to financial services-firm performance relationship.

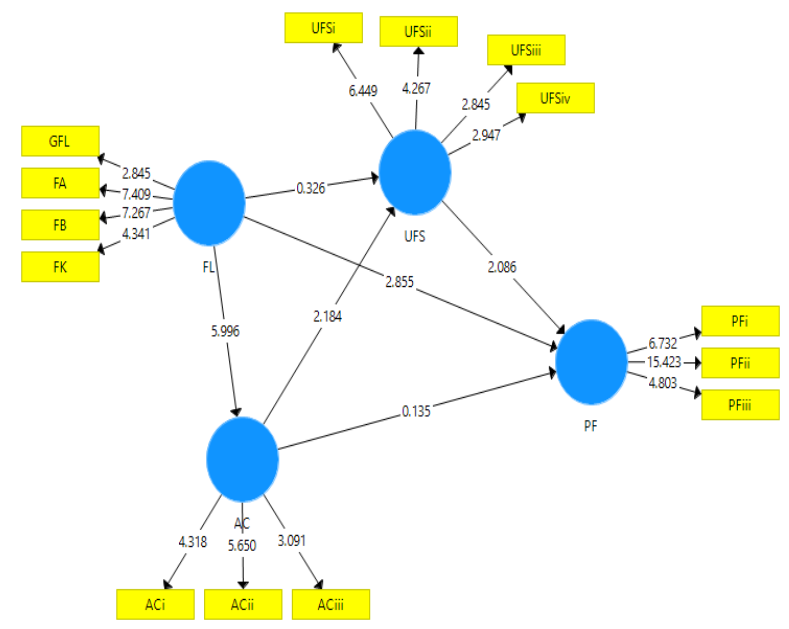

Fig. 2. Results after Bootstrapping

The fact that we had insignificant results in some relationship in our model and exploring further inferences we examine the supposedly mediation role of the firm managers use of financial services into the financial literacy-firm performance and access to finance-firm performance relationship. Hence we have $\mathrm{H}_{5}$ and $\mathrm{H}_{6}$ to do this we use the Sobel test of mediation available online at https://www.danielsoper.com.The Sobel test of mediation uses three formulas to calculate the mediation:

The first formula is the error function

$$
\operatorname{erf}(\mathrm{x})=\frac{2}{\sqrt{\pi}} \int_{0}^{\mathrm{x}} \mathrm{e}^{-\mathrm{t}^{2}} \mathrm{dt}
$$

The second formula is the normal distribution cumulative distribution function (CDF)

$$
\mathrm{F}\left(\mathrm{x} ; \mu, \boldsymbol{\delta}^{2}\right)=\frac{1}{2}\left[1+\operatorname{erf}\left(\frac{\mathrm{x}-\mu}{\boldsymbol{\delta} \sqrt{2}}\right)\right]
$$

Where $\mu$ is the mean, $\delta$ is the standard deviation and 'erf' is the error function.

Sobel test statistic:

$$
\mathrm{Z}=\frac{\mathbf{a b}}{\sqrt{\mathbf{b}^{2} \mathbf{S E}_{\mathbf{a}}^{2}+\mathbf{a}^{2} \mathbf{S E}_{\mathbf{b}}^{2}}}
$$

Where ' $a$ ' is the regression coefficient for the relationship between the independent variable and the mediator ' $b$ ' is the regression coefficient for the relationship between the mediator and the independent variable, $\mathbf{S} \boldsymbol{E}_{\boldsymbol{a}}^{\mathbf{2}}$ is the standard error of the relationship between the independent variable and the mediator and $\mathbf{S} \boldsymbol{E}_{\boldsymbol{b}}^{\mathbf{2}}$ is the standard error of the relationship between the mediator variable and the independent variable.

Using this approach then we test $\mathrm{H}_{5}$ and $\mathrm{H}_{6}$

$\mathrm{H}_{5}$ Predicted that the SMEs firm use of financial services mediate financial literacy-firm performance relationship in developing economies. From our model we have the firm performance (PF) as the dependent variable, use of financial services (UFS) as the mediator and financial literacy (FL) as independent variable. We have the original sample path coefficient FL-> UFS is 0.044 and the standard error is 0.136 , the original sample path coefficient for UFS->PF is 0.236 and the standard error is 0.097 . Therefore we input these data into the online Sobel test and we get $\mathrm{Z}=0.32037257$, one tailed probability $=0.37434296$ and two tailed probability $=$ 0.74868591 . Our results shows insignificant mediation role of the use of financial services and on the relationship of financial literacy and the firm performance. Therefore $\mathrm{H}_{5}$ is not supported.

$\mathrm{H}_{6}$ Also projected that the use of financial services mediate the access to finance-firm performance relationship in developing economies. The firm performance is our dependent variable, the use of financial services is the mediating variable and access to financial services is the independent variable. From our results we have the following data:

The original sample path coefficient for AC->UFS is 0.298 and the standard error is 0.052 , the path coefficient for UFS$>\mathrm{PF}$ is 0.236 and the standard error is 0.097 . Inputting the data in the Sobel test we yield $\mathrm{Z}=2.13368290$, one tailed probability $=0.01643437$, and the two tailed probability $=$ 0.03286875 . The results is significant at $p<0.05$ indicating that the use of financial services significantly explain the relationship between access to financial services and firm performance. Therefore H6 is supported.

\section{A. Discussion of the Results}

The objective of this study was to examine the SMEs financial literacy, access to financial services, use of financial services influence each other and the eventual impact on firm performance. Our study offer evidence of the significant results between financial literacy and access to finance, financial literacy and financial performance. The results cement evidences of the positive impact of financial literacy on either firm access to financial services and ultimately improves SMEs performance, access to financial service and the use of financial services and financial performance. Our findings is in conformity with prior studies of [24], [61]-[63]

Also our study finds that the use of financial services significantly mediate the relationship between access to financial services and firm performance, such that the effect impact of access to financial services on firm performance is more explained when there is use of financial services by the SMEs. Our results implies that use of financial services significantly justify the causal order of access to financial services on firm performance such that the higher the use of financial services the more clearer we can appreciate the impact of access to financial services on firm performance. 
The results are profound contribution to scholarly literatures on how we can understand and review the variables relationships in our model. The literature confirms that there is positive impact of access to financial services to firm performance [64]-[67] but none of these tried to examine the anticipated effect of the mediating role of the actual use of financial services.

Our model also reveal that there is an insignificant between financial literacy to use of financial services, this may speculatively explains that even though awareness of financial resources remain to be an important driver for use such services some other social and economic factors might influence individuals and firm on the actual use, and also the same applies to access to financial services-firm performance relationships which might be insignificant as well.

Our model uncover that there is insignificant mediating role of use of financial services on the financial literacy-firm performance relationship. This implies that use of financial services has insignificant explanation of the awareness of funding sources and firm performance relationships. In other words the causal order between financial literacy and firm performance is immaterially explained by the use of such financial services. The results makes sense because there is significant positive direct relationship of financial literacy-firm performance path.

Many studies have treat access and use of financial services as a single variable, by breaking down these parts our study brings down a more thorough interplay analysis of the financial accessibility and usability issues facing individuals and firms and therefore add to the body of literature.

\section{CONCLUSIONS}

Even though there are ample efforts by the governments, private sectors, regional and multilateral organizations, there is still more to be done when it comes to SMEs performance improvements. SMEs managers at personal level still need to have more knowledge and insight on how they manage the finances of their venture. Need more flexible mindset to match with the pace of the growth of the finance supply side for their firm sustenance. For SMEs in developing countries to thrive there is a need to improve more aggressive efforts need to be implemented in terms of personal initiative training, the funding suppliers which includes the formal banks, microfinances, governments agencies and NGOs need widen their scope of financial literacy not only to their customers but also to the wider community. While providing education it is important to fight the barrier towards access to financial services monitoring the actual use of the financial products by firms and noting the reasons for non uses. Boosting the competitive behavior of the financial institutions would result into ample supply of financial services to SMEs and lowincome households at less costs of intermediation.

\section{REFERENCES}

[1] E. Lukács, "The economic role of SMEs in world economy, especially in Europe," European integration studies, vol. 4, pp. 3-12, 2005.

[2] K. Hayes, "SMEs and the Economy," in Business Journalism, ed: Springer, 2014, pp. 175-185.

[3] L. I. Savlovschi and N. R. Robu, "The role of SMEs in modern economy," Economia, Seria Management, vol. 14, pp. 277-281, 2011.
[4] S. Ahmed, "the role of SMEs in developing economy," Abuja, Omotayo and co. 1td, 2006.

[5] G. S. Fields, "Labor market analysis for developing countries," Labour Economics, vol. 18, pp. S16-S22, 2011.

[6] A. F. Gockel and S. K. Akoena, Financial Intermediation for the Poor: Credit Demand by Micro Small and Medium Scale Enterprises in Ghana: a Further Assignment for Financial Sector Policy?: ILO, 2002.

[7] J. Abor and P. Quartey, "Issues in SME development in Ghana and South Africa," International Research Journal of Finance and Economics, vol. 39, pp. 215-228, 2010.

[8] K. Dalitso and Q. Peter, "The policy environment for promoting small and medium-sized enterprises in Ghana and Malawi," University of Manchester, 2000.

[9] G. F. Udell, "SME Access to intermediated credit: What do we know and what don't we know," in Reserve Bank of Australia, Proceedings of Small Business Conditions and Finance Conference, 2015, pp. 61-109.

[10] S. Spinelli and H. Neck, "The Timmons model of the entrepreneurial process," Entrepreneurship: The Engine of Growth, vol. 2, p. 6, 2007.

[11] L. Guiso and T. Jappelli, "Awareness and stock market participation," Review of Finance, vol. 9, pp. 537-567, 2005.

[12] J. Nunoo and F. K. Andoh, "Sustaining Small and Medium Enterprises through Financial Service Utilization: Does Financial Literacy Matter?," in Annual Meeting, 2012.

[13] A. Demirgüç-Kunt, L. F. Klapper, D. Singer, and P. Van Oudheusden, "The global findex database 2014: Measuring financial inclusion around the world," 2015.

[14] N. A. Waithaka J.M, "Effects of Informal Finance on the Performance of Small and Medium Enterprises in Kiambu County," International Journal of Scientific and Research Publications, vol. 5, 2015.

[15] R. Cull and K. Scott, "Measuring household usage of financial services: does it matter how or whom you ask?," the world bank economic review, vol. 24, pp. 199-233, 2010.

[16] A. Grohmann, T. Klühs, and L. Menkhoff, "Does Financial Literacy Improve Financial Inclusion? Cross Country Evidence," 2017.

[17] M. I. Wachira and E. N. Kihiu, "Impact of financial literacy on access to financial services in Kenya," International Journal of Business and Social Science, vol. 3, 2012.

[18] A. Atkinson and F.-A. Messy, "Promoting financial inclusion through financial education," OECD Working Papers on Finance, Insurance and Private Pensions, p. 1, 2013.

[19] H. A. Simon, "Theories of bounded rationality," Decision and organization, vol. 1, pp. 161-176, 1972.

[20] R. Rugimbana and E. Kojo Oseifuah, "Financial literacy and youth entrepreneurship in South Africa," African journal of Economic and management studies, vol. 1, pp. 164-182, 2010.

[21] M. Van Rooij, A. Lusardi, and R. Alessie, "Financial literacy and stock market participation," Journal of Financial Economics, vol. 101, pp. 449472, 2011.

[22] BBB, "Small Business Finance Market," ed: British Business Bank, 2015.

[23] A. A. Eniola and H. Entebang, "Financial literacy and SME firm performance," International Journal of Research Studies in Management, vol. 5, 2015.

[24] O. O. Fatoki and F. Asah, "The impact of firm and entrepreneurial characteristics on access to debt finance by SMEs in King Williams' Town, South Africa," International Journal of Business and Management, vol. 6, p. 170, 2011.

[25] S. Claessens, "Access to financial services: a review of the issues and public policy objectives," The World Bank Research Observer, vol. 21, pp. 207-240, 2006.

[26] T. Beck, A. Demirguc-Kunt, and M. S. M. Peria, "Reaching out: Access to and use of banking services across countries," Journal of Financial Economics, vol. 85, pp. 234-266, 2007.

[27] J. Talledo, "Access To And Use Of Financial Services: Evidence From Peru," 2015.

[28] T. Beck and A. De la Torre, The basic analytics of access to financial services: The World Bank, 2006. 
[29] G. I. Nwanna, "Financial Accessibility And Rural Sector Development/Accès Au Financement Et Developpément Du Secteur Rural," Savings and Development, pp. 453-491, 1995.

[30] A. Hung, J. Yoong, and E. Brown, "Empowering women through financial awareness and education," OECD Working Papers on Finance, Insurance and Private Pensions, p. 1, 2012.

[31] P. Marriott, "An Analysis of First Experience Students' Financial Awareness and Attitude to Debt in a Post-1992 UK University," Higher Education Quarterly, vol. 61, pp. 498-519, 2007.

[32] D. Ramasamy, T. Savilla, S. Anoop, and M. Ramen, "A study of the level of awareness of financial literacy among management undergraduates," Google Scholar, 2013.

[33] A. Demirgüç-Kunt, T. Beck, and P. Honohan, Finance for all?: Policies and Pitfalls in Expanding Access: World bank, 2008.

[34] A. Demirguc-Kunt, T. Beck, and P. Honohan, "Access to Finance and Development: Theory and Measurement," Finance for All? Policies and Pitfalls in Expanding Access. The World Bank, p. 22, 2008.

[35] K. Chakrabarty, "Financial Inclusion in India-Journey So Far and Way Forward," Keynote Address at the Finance Inclusion Conclave. Organized by CNBC TV, vol. 18, 2013.

[36] B. A. Iqbal and S. Sami, "Role of banks in financial inclusion in India," Contaduría y Administración, vol. 62, pp. 644-656, 2017.

[37] T. Arun and R. Kamath, "Financial inclusion: Policies and practices," IIMB Management Review, vol. 27, pp. 267-287, 2015.

[38] A. Sjauw-Koen-Fa and I. Vereijken, "Access to financial services in developing countries," Rabobank Nederland, September, pp. 1-32, 2005.

[39] F.-A. Messy and C. Monticone, "The status of financial education in Africa," 2012.

[40] BASA, "Save for Better Future," ed. Johanmrsburg, South Africa: Banking Association in South Africa 2011.

[41] UN, "The millennium development goals report 2009," E. a. P. information, Ed., ed: United Nations Publications, 2009.

[42] P. Dahmen and E. Rodríguez, "Financial literacy and the success of small businesses: An observation from a small business development center," Numeracy, vol. 7, p. 3, 2014.

[43] A. A. Eniola and H. Entebang, "SME Managers and Financial Literacy," Global Business Review, p. 0972150917692063, 2017.

[44] B. Fowowe, "Access to finance and firm performance: Evidence from African countries," Review of Development Finance, vol. 7, pp. 6-17, 2017.

[45] L. Chauvet and L. Jacolin, "Financial Inclusion, Bank Concentration, and Firm Performance," World Development, vol. 97, pp. 1-13, 2017.

[46] U. r. o. Tanzania, "Small and Medium Enterprises Dvelopment Policy," M. o. i. a. Trade, Ed., ed. Tanzania, 2003.

[47] F. Olawale, "The financial literacy of Micro Enterpreneurs in South Africa," Journal of social sciences, vol. 42, p. 7, 2014.

[48] D. A. Adomako S, "Financial Literacy and firm Performance: the Moderating role of financial Capital availability and Resource Flexibility," International Journal of Management and Organizational studies, vol. 3, 2014.

[49] H. Latan and N. A. Ramli, "The Results of Partial Least Squares-
Structural Equation Modelling Analyses (PLS-SEM)," 2013.

[50] J. F. Hair, M. Sarstedt, C. M. Ringle, and J. A. Mena, "An assessment of the use of partial least squares structural equation modeling in marketing research," Journal of the academy of marketing science, vol. 40, pp. 414433, 2012.

[51] C. Fornell and F. L. Bookstein, "Two structural equation models: LISREL and PLS applied to consumer exit-voice theory," Journal of Marketing research, pp. 440-452, 1982.

[52] R. P. Bagozzi, Y. Yi, and K. D. Nassen, "Representation of measurement error in marketing variables: Review of approaches and extension to three-facet designs," Journal of Econometrics, vol. 89, pp. 393-421, 1998.

[53] J. Hulland, "Use of partial least squares (PLS) in strategic management research: A review of four recent studies," Strategic management journal, pp. 195-204, 1999.

[54] W. Kwong, "Partial Least Square Structural Equation Modelling (PLSSEM) Techniques Using SmartPLS," Marketing Bulletin, vol. 24, 2013.

[55] C. Fornell and D. F. Larcker, "Evaluating structural equation models with unobservable variables and measurement error," Journal of marketing research, pp. 39-50, 1981.

[56] W. W. Chin, "The partial least squares approach to structural equation modeling," Modern methods for business research, vol. 295, pp. 295-336, 1998.

[57] D. Garson, Partial Least Square: Regression and Structural Equation Models. North Carolina State University: Statistical Associates 2016.

[58] P. M. Podsakoff, S. B. MacKenzie, J.-Y. Lee, and N. P. Podsakoff, "Common method biases in behavioral research: a critical review of the literature and recommended remedies," Journal of applied psychology, vol. 88, p. 879, 2003.

[59] H. Liang, N. Saraf, Q. Hu, and Y. Xue, "Assimilation of enterprise systems: the effect of institutional pressures and the mediating role of top management," MIS quarterly, pp. 59-87, 2007.

[60] N. Kock, "Common method bias in PLS-SEM: A full collinearity assessment approach," International Journal of e-Collaboration (IJeC), vol. 11, pp. 1-10, 2015.

[61] F. Olawale and D. Garwe, "Obstacles to the growth of new SMEs in South Africa: A principal component analysis approach," African journal of Business management, vol. 4, p. 729, 2010.

[62] J. Abor and N. Biekpe, "Small business financing initiatives in Ghana," Problems and Perspectives in Management, vol. 4, pp. 69-77, 2006.

[63] O. O. Fatoki, "The impact of human, social and financial capital on the performance of small and medium-sized enterprises (SMEs) in South Africa," Small, vol. 50, p. R4m, 2011.

[64] A. W. Butler and J. Cornaggia, "Does access to external finance improve productivity? Evidence from a natural experiment," Journal of Financial Economics, vol. 99, pp. 184-203, 2011.

[65] M. M. Rahaman, "Access to financing and firm growth," Journal of Banking \& Finance, vol. 35, pp. 709-723, 2011.

[66] T. Beck and A. Demirguc-Kunt, "Small and medium-size enterprises: Access to finance as a growth constraint," Journal of Banking \& finance, vol. 30, pp. 2931-2943, 2006.

[67] R. Atieno, Linkages, access to finance and the performance of small-scale enterprises in Kenya: Research paper/UNU-WIDER, 2009. 